\title{
Quest for improving service life of asphalt roads
}

\author{
Manfred N. Partt $1^{1,2,3 *}$ \\ ${ }^{1}$ Empa, Swiss Federal Laboratories for Materials Science and Technology, $\mathrm{CH}-8600$ Duebendorf, Switzerland \\ ${ }^{2}$ KTH Royal Institute of Technology, SE-10044 Stockholm Sweden \\ ${ }^{3}$ Carleton University Ottawa, ON Canada K1S 5B6
}

Received: 17 March 2020 / Accepted: 09 April 2020 / Published online: 23 April 2020

(C) The Author(s) 2020. This article is published with open access and licensed under a Creative Commons Attribution 4.0 International License.

\begin{abstract}
Selected results and initiatives in modern asphalt pavement research for increasing service life of asphalt pavements under the aspect of sustainability and multifunctional use of roads are summarized. Focus lies on innovative approaches and own experience, jointly elaborated during the last decades within the road engineering/sealing components lab at Empa and both the highway/railways engineering and building materials group at KTH. This includes material concepts and design as well as pavement system and construction aspects from an experimental and modelling point of view. It includes also the application of powerful experimental and computational tools, such as Atomic-Force-Microscopy (AFM), X-Ray-Computer-Tomography (CT), DigitalImaging-Correlation (DIC) and Discrete-Element-Method (DEM). As for materials, recycling issues and the use of Phase-Change-Materials (PCM) or metallic ingredients for inductive thermal crack healing are addressed. In order to remind that material design must also account for the workability during the process of compaction, the new Compaction-Flow-Test (CFT) developed at KTH is shortly presented. Innovative ideas for structural material composition are also mentioned, such as "artificial aggregates" or "additive manufacturing", being aware that there is still a long way to go. Regarding pavement systems, ideas for multifunctional road applications are proposed. Focus is also put on special issues, such as construction joints.
\end{abstract}

Keywords: Asphalt; Roads; Innovation; Research; Service Life

\section{Introduction}

Asphalt pavement technology has experienced dynamic progress in the last decades from both a technical and scientific point of view. On the one hand the development and application of new materials has led to a wide diversity of new tailor-made bituminous materials, opening new potential ways of increasing service life and multifunctional use of roads, e.g. for carrying traffic loads as well as harvesting energy. On the other hand it has led to a leap forward towards in-depth understanding of the chemo-physical and mechanical behavior of bituminous road materials, thus turning asphalt research from a mainly phenomenological experience driven low tech to a scientifically demanding and innovation boosting "high-tech" subject. These challenging but, nevertheless, exciting developments, were governed by increasing expectations and requirements regarding inservice performance of road materials within today's difficult socio-economic and climate-ecologic environment, in particular with respect to sustainable development in favour of future generations and the awareness of being responsible for a careful use of the limited material resources worldwide. This paper gives examples of selected efforts and research initiatives in that direction during the last decades based on own experience and involvement in projects within the road engineering/sealing components lab at Swiss Federal Laboratories for Material Science and Technology (Empa) [3, $8-23,27]$ and both the highway/railways engineering and building materials group at Swedish Royal Institute of Technology (KTH) [24-28]. Some of these activities are closely linked to the work within different international technical committees of the International Union of Laboratories and Experts in Construction Materials, Systems and Structures (Rilem), e.g. [1, 4-6], and the International Society for Asphalt Pavements (ISAP) with its technical committee Asphalt Pavement and Environment (ISAP TC APE), e.g. [7].

Within the frame of these research initiatives, different modern powerful experimental and computational research tools were applied and evaluated, such as Atomic-ForceMicroscopy (AFM), X-Ray-Computer-Tomography (CT), Environmental Scanning Electron Microscopy (ESEM), DigitalImaging-Correlation (DIC), Attenuated Total Reflectance Fourier Transform Spectrometer (ATF-FTIR), Finite Element Method (FEM), Discrete-Element-Method (DEM), ArtificialNeural-Network (ANN) and Lattice-Boltzmann-Method (LBM). Moreover, Accelerated Pavement Testing (APT) with Mobile Load Simulator (MLS) for simulating full-scale traffic

* Corresponding author: Manfred N. Partl, Email: manfred.partl@empa.ch 
loads and Model Mobile Load Simulator (MMLS) was applied for validating the effectiveness of innovative pavements [2].

The main overall motivation for the above mentioned research initiatives at Empa and $\mathrm{KTH}$ was to improve service life of asphalt materials and roads, always keeping in mind the positive properties of asphalt in terms of recyclability and the generally accepted fact that durability is the most important factor for fulfilling sustainability requirements. This durability is considerably influenced not only by mechanical loading conditions, which may create rutting or fatigue, thermal and compaction induced cracking, but also by long-term environmental effects, such as oxidative aging of bitumen due to permanent exposure to air, UV solar radiation and water penetrating into the asphalt either through diffusion or direct infiltration into pores or existing cracks.

One challenge in performing research in that direction, at least in parts of Europe, is the growing environmentally driven opposition against "paving the landscape from green to grey" which is in some contradiction to the social expectations of prosperity and comfort as well as the still existing "low-tech" image of paving technology in the general public. This situation leads to both political reluctance in providing research and development funding and in promoting academic education of young professionals.

Another significant challenge in performing research in that direction is the gap in thinking and communication between "hard hats" and "egg heads" in our domain. On one side, we have the standardization- and tradition-oriented practitioners, who are working under real "dirty" field conditions, aiming at realizing technically and economically effective application-oriented specific road construction solutions. On the other side, we have the research-oriented academics and laboratory experts, who are working under ideal, well defined "clean" conditions, searching for a universal in depth understanding, and modelling of materials in a more scientific and sustainable way on the other hand.

In order to close this gap, it is important to consider the whole chain of knowledge from cradle to grave, i.e. from production to construction to maintenance to recycling and to disposal. This requires also changing the level of interest as needed from nano- to macro-scale or from single components, such as bituminous binder and mineral aggregate alone, to the whole asphalt composite and even the whole anisotropic multilayer pavement system. It includes material concepts and design as well as pavement system and construction aspects from an experimental and modelling point of view.

A summary of the main asphalt materials concepts is given in Fig.1, where it is schematically shown that stones can be hold together by three principal mechanisms, i.e. gluing, friction and confinement [1]. Depending on which stone structure is dominant, the resulting mixture is a mastic, packing or skeleton type of asphalt. Each type is showing different mechanical behavior and requires different test methods.
Apart from the well-known traditional factors, the quality of pavements produced with these mixtures is influenced by the material resources (e.g. Reclaimed Asphalt Pavement - RAP, waste components and marginal materials), the production and construction temperatures (hot, warm and cold) and the way of placing (e.g. paver, additive manufacturing and prefabrication).

\section{Recycling}

Quality and percentage of the RAP material is considerably influencing durability and service life of asphalt pavements. This is particularly true with respect to repeated recycling and the type of rejuvenator used. As for repeated recycling, joint research between Empa and the Public Works Research Institute PWRI in Japan [8] demonstrated that repeated RAP recycling is difficult to simulate in the lab, in particular regarding aggregate damage during milling and regarding realistic aging which, in reality, is influenced not only by oxidation but many other factors such as UV and moisture. Nevertheless, with respect to service life, it was positive to observe in the lab that repeated hot recycling, up to a RAP content of $40 \%$, was of negligible effect, because the added new hot mixture material dominated the behavior. However, with higher RAP contents, the behavior after several recycling stages became complex and difficult to predict, particularly when rejuvenating agents had to be added. On the binder side, this is partly due to the fact that rejuvenators cannot totally restore the original binder of the RAP component and the way of how the rejuvenator effect disappears over time, differs from the aging mechanism of the binder itself. This was demonstrated also in a PhD project with bio-based rejuvenators at Empa [9].

During this PhD study, thickness distribution of the residual RAP binder film on typical crushed aggregates were measured with ESEM. It was found that, in this specific case, the RAP binder film thickness varied between 1 and $6 \mu \mathrm{m}$ at $140^{\circ} \mathrm{C}$ and only between 1 and $3 \mu \mathrm{m}$ at $180^{\circ} \mathrm{C}$, demonstrating that the mixing temperature has a significant effect on the interaction between newly added and RAP binder [10]. In another research on binder surface topography with AFM (Fig. 2.), RAP binder was compared with artificially aged, original and water treated pen graded $70 / 100$ bitumen. It was found that the so called "Bee-structures" were no longer visible on RAP binder, extracted with toluene, whereas aging in the Pressure Aging Vessel (PAV) produced a denser and water treatment an eroded "Bee-Structure" [11]. Although these micro-scale observations are far from being related to service life of a pavement, and in case of RAP binder probably also influenced by the extraction solvent, they provide evidence of the complex processes that may influence the performance of a binder in a mixture. 


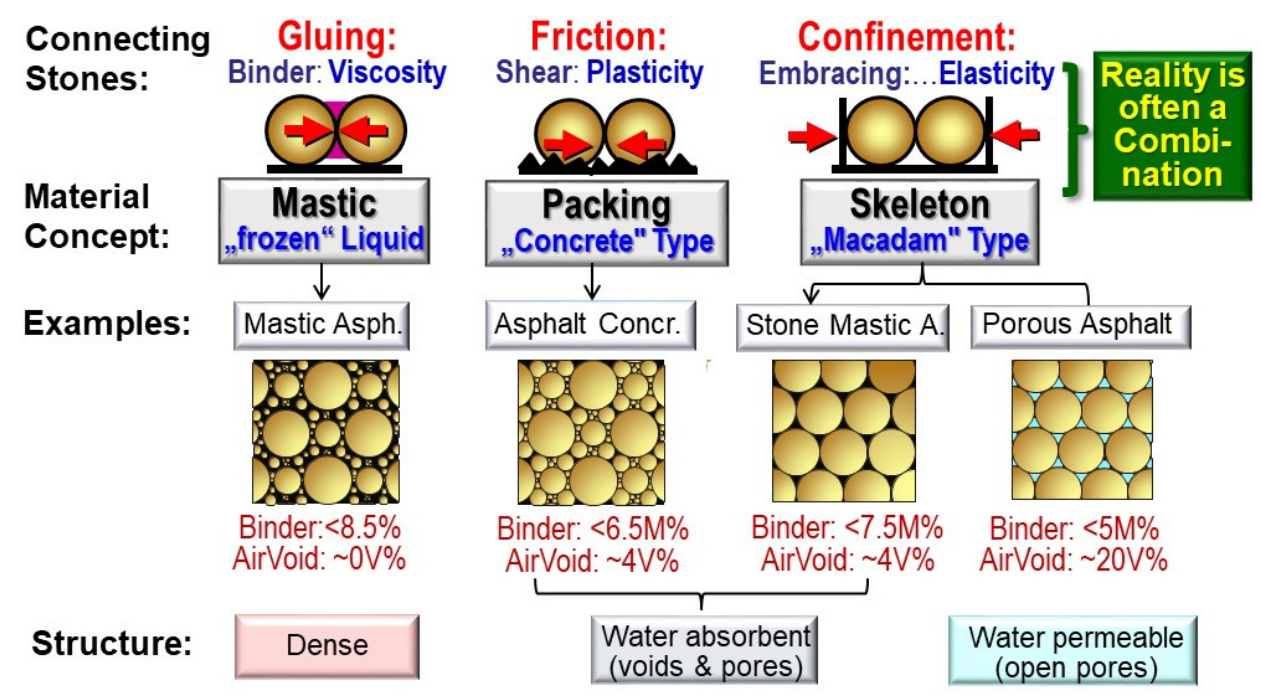

Figure 1. Basic asphalt material concepts.



Figure 2. AFM Bitumen topography, after $20 \mathrm{~min}$ annealing at $110^{\circ} \mathrm{C}$ and (if not water conditioned) left at room temperature $24 \mathrm{~h}$ before $\mathrm{AFM}$; $15 \mu \mathrm{m}^{2}$ are visible.

In fact, correlation between findings in the laboratory and the real in field behavior is quite a tricky subject. In an extended research project for the Swiss Federal Road Office (FEDRO) it was found that mixtures with high RAP content, optimized in the lab under defined conditions to similar performance than hot asphalt without RAP, did not perform as expected in the field under accelerated pavement tests $[12,13]$. One field section with RAP consisted of a $60 \%$ RAP surface course on a new base course and the other one of a 75\% RAP base course without surface course. Under APT with MLS, both pavements with RAP showed significantly heavier damage and therefore a lower service lifespan than the corresponding sections without RAP. These differences were partly attributed to material deficiencies due to plant production as well as in-field construction issues, such as compaction and temperature inhomogeneities.

\section{Material design and modifications \\ 3.1 Thermal crack healing}

One strategy for increasing service life is the introduction of ferro-metallic ingredients into the mixture for future inductive thermal crack healing of a pavement by externally activating the intrinsic healing potential. This can be done either through low frequency induction at $78 \mathrm{kHz}$ in case of micro-scale steel particles [14] or high frequency alternating magnetic fields at $285 \mathrm{kHz}$ in case of magneto-sensitive particles close to nano-scale [15]. The idea is to induce local heating such that the viscosity of bitumen is reduced for filling small cracks (Fig 3). A similar crack healing effect may also occur naturally due to elevated summer temperatures, but since this uncontrolled "self-healing" capability may increase the risk of traffic induced rutting, it is normally reduced by designing sufficiently stiff pavements with high resistance to permanent deformation. 
Fig 3, shows digital imaging correlation (DIC) strain measurement results of a double torsion test before and after inductive healing. In this case, almost complete healing and crack closing could be achieved.

Induction heating may be successfully repeated periodically for extending service life [16]. Slabs 1800 x 435 x 40 cm with two $10 \mathrm{~mm}$ deep transversal central groves at a distance of $190 \mathrm{~mm}$ lying on a rubber bed between two stiff supports were loaded with the MMLS as shown in Fig 4. Vertical deformation during wheel passings was measured with LVDT displacement sensors. The slabs consisted of asphalt concrete AC8 with $14 \%$ wt (of mixture) iron particles of $0.6 . .1 .0 \mathrm{~mm}$ diameter. Crack healing was performed with a $30 \mathrm{~kW}$ inductive heater at a maximum frequency of $80 \mathrm{kHz}$ creating a healing temperature of $80^{\circ} \mathrm{C}$ according to measurements with a an infrared camera. After healing, the slab was allowed to cool down to room temperature for continuation of the accelerated pavement testing.

In this specific case, a lifetime increase of about $70 \%$ was achieved after each healing by induction treatment. As shown in Fig. 4, the slope $m$ of the vertical deformation curves after each healing remained in the same order of magnitude. However, the slope became significantly higher after macrocrack initiation immediately before failure. Note, that during cyclic loading and damage accumulation, the temperature of the slabs gradually increased in the order of $5^{\circ} \mathrm{C}$ due to the energy dissipation within the viscoelastic asphalt slabs. Applying induction healing 3 times, whenever reaching a vertical deformation of ca. $0.75 \mathrm{~mm}$, extended the overall service lifetime by about $200 \%$.

\subsection{Phase change materials}

Another potential strategy of increasing service life is the introduction of phase change materials (PCM). In a theoretical study together with the University of Applied Science and Arts in Lucerne it was shown that, $8 \mathrm{~cm}$ below the pavement surface, the potential of lowering the temperature in an asphalt concrete with $15 \%$ PCM Icosane (melting temperature $36.6^{\circ} \mathrm{C}$ ) is about $4^{\circ} \mathrm{C}$, at daytime in summer [17]. Test in the laboratory were performed with PCM Tetradecane $\mathrm{C}_{14} \mathrm{H}_{30}$ (melting point 4 to $6^{\circ} \mathrm{C}$ ) on binder alone and on mixtures with microencapsulated PCM.

It was found that adding pure Tetradecane into binder produced binder softening without showing any phase change effect [18]. However, when using microencapsulated PCM in bitumen alone, or as 9 vol\% filler replacement in Marshall specimens, phase change occurred [19]. Ongoing research deals with $\mathrm{PCM}$ impregnated porous aggregates with cement coating, such as foam glass, in order to increase the total volume of PCM in the mixture, being fully aware that extended research will be needed for obtaining suitable impregnable aggregates with high mechanical resistance during the whole long-term service life.

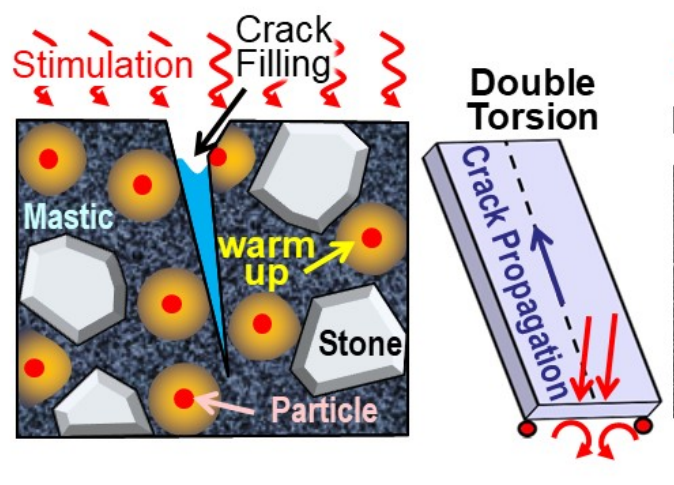

\section{Digital Imaging Correlation DIC}

\section{Before Healing After Healing}

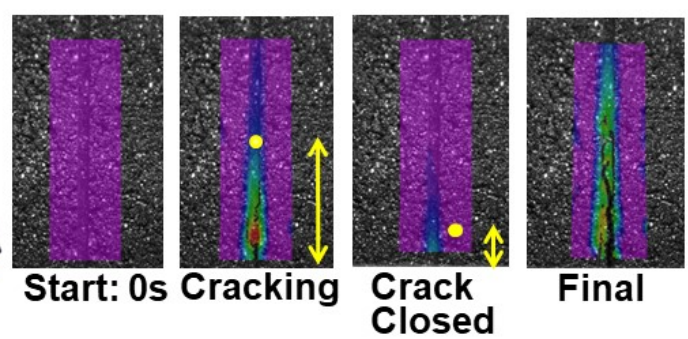

Figure 3. Principle of inductive crack healing and double torsion DIC result.
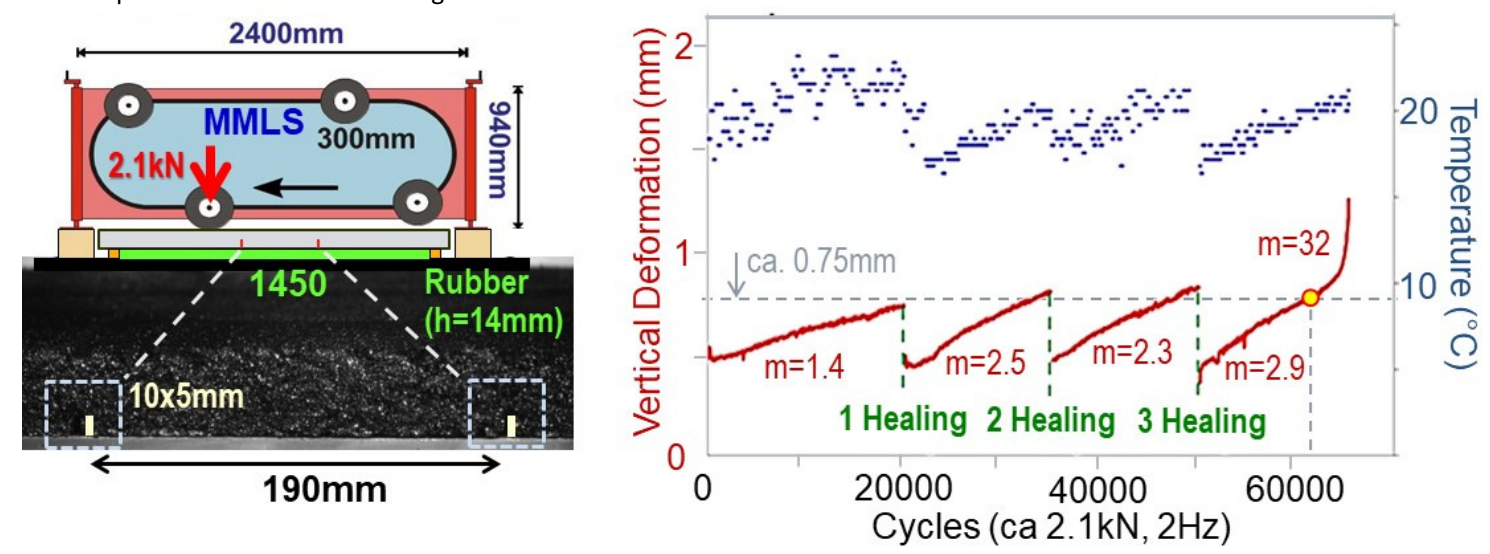

Figure 4. Vertical permanent deformation and slopes $(\mathrm{m})$ due to MMLS loading before and after repeated inductive healing; also shown is the temperature evolution 


\subsection{Artificial aggregates}

Modification and design of materials is not limited to classical asphalt composites. Ongoing projects at Empa deal with artificial aggregates and systems for robotic string reinforcement of pavements. These projects are strongly relying on numerical tools, such as DEM, for theoretical design of solutions that will be validated in the laboratory with experimental model testing. Reports are in preparation and will be published soon.

The idea of artificial aggregates has its origin in the need for producing multifunctional pavements with both a strong load bearing skeleton structure and a maximum of large communicating voids. These voids should have minimal tortuosity and allow long-term circulation of other media within the pavement layer, such as water, for transporting energy from solar energy harvesting without the necessity of using a pipe system. Such a concept could also be useful for mitigating urban heat island effects. It should be designed such that the risk of clogging and the maintenance effort for flushing the system are minimized.

As proposed in [1] and shown in Fig. 5a, one solution could be to imprint meandering pipe-like water channels into a waterproof mastic asphalt pavement layer, filling the imprinted channels with strongly gap graded stones or with artificial aggregates in order to obtain a load-resistant unbound skeleton of high continuous pore volume for water flow. Artificial aggregates in the imprinted channels could be hollow tetrahedrons or dolos and tetrapods fabricated with $3 \mathrm{D}$ printing, e.g. as complex $\mathrm{Al}_{2} \mathrm{O}_{3}$ ceramic structures [22], or with other techniques, still to come. This imprinted channel system should then be covered with a thin waterproof, probably reinforced, black surface layer that is exposed to solar radiation.

Optimization of the free void configuration within the unbound structural skeleton of the channels could profit from two recently completed PhD theses under the leadership of the Empa laboratory for Multiscale Studies in Building Physics. There, water flow and drying within porous asphalt has been intensively investigated and modelled based on microcomputed tomography (X-ray $\mu-\mathrm{CT}$ ) images and wind channel measurements as well as numerical analysis with a pore network modelling (PNM) and kinetic lattice Boltzmann modelling (LBM) $[20,21]$. It is clear that development of such pavements is still far from being realized for practical applications. On the one hand, cost effective technology for industrially fabricating large amounts of suitable artificial aggregates is still not available; on the other hand, suitable binders must be developed that allow long-term water resistant bond without reducing the volume of the voids significantly. Nevertheless, given the practical advantage in terms of recyclability without having to deal with embedded metal or plastic pipes and for potentially easier construction and repair, it appears reasonable to continue developments in that direction.

\subsection{Robotic string reinforcement}

The concept of robotic reinforcement of pavements is based on work at the Swiss Federal Institute of Technology ETH [23]. Instead of bituminous binder, flexible reinforcing tensile strings, produced on the spot by extruders on robotic arms, are placed in a $3 D$ way following the most convenient patterns for holding together the unbound aggregates without the need of binders or external confinement, as shown schematically in Fig $5 b$. The motivation for this new type of pavements is not only increasing their service life but also fostering saving and re-use of raw materials by reducing the amount of required binder and by allowing an almost immediate re-use of aggregates.

a

b

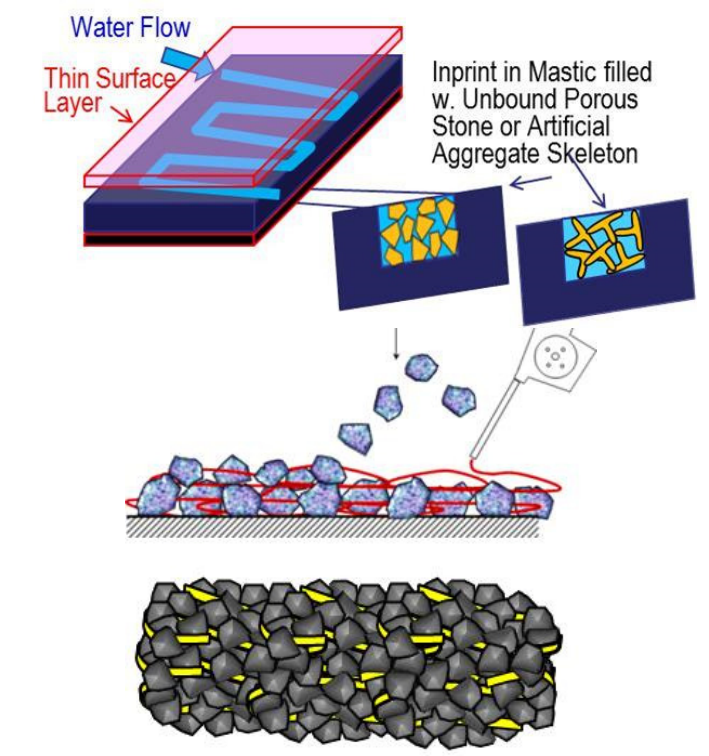

Figure 5. a) Principle of imprinted channels in mastic asphalt as replacement of pipes for energy harvesting; b) principle of reinforcing pavements with robotic string placing

Ongoing research at Empa aims at providing a proof of concept for this idea of road construction [24]. Theoretical analysis with DEM for evaluating suitable combinations of aggregates and string reinforcement combined with mechanical tests in the laboratory using pre-fabricated strings have started and are promising. Again, it is clear that this kind of pavement is still far from being ready for use and still needs considerable research effort. However, it is considered as one environmental friendly possibility on the quest for improved multifunctional and more durable alternatives for traditional asphalt.

\section{Pavement construction aspects 4.1 Challenges}

The construction phase is one key to improved service life of asphalt pavements. However, as compared to research on compacted materials and asphalt roads, research efforts in that direction are still surprisingly limited. This is particularly true with respect to workability and compactibility issues, as well as challenges related to the construction of pavement 
joints. Moreover, these topics are mostly understood as phenomenologically based practical trial and error domains of contractors and asphalt plant operators, where the academic research community can only partially contribute. In fact, we may have here the most prominent borderline between the above mentioned "hard hats" and "egg heads". This is certainly not due to missing interest of the different players; but linking practice and real life situation at 1:1 scale with modelling and academic approaches at lab scale is certainly a significant challenge in this case. Major reason is the almost unlimited variety of influence factors, such as local construction conditions in terms of climate and topography, time and financial restraints, construction equipment, individual craftsmanship and quality matters (e.g. material inhomogeneity) etc.. Nevertheless, since pavement structures and materials become more and more diverse, this borderline situation has to change for the sake of reducing the risk of unexpected loss of service life.

Recently, KTH has undertaken different research initiatives on these matters, aiming at reducing the lack of knowledge and elaborating a scientific basis particularly in view of simulating and better understanding the mechanical processes, such as material flow and segregation, within the asphalt during transport and compaction. Both processes are characterized by large movements at hot temperatures and therefore predestined for DEM modelling and applications. Another focus was laid on studies for improving service life of construction joints when building new roads or when replacing only parts of a pavement. The research on joints was performed in parallel with research at Empa, evaluating possibilities of improving service life of joints by applying inductive healing as discussed below.

\subsection{Slump performance and segregation}

With respect to workability and segregation of uncompacted asphalt mixtures, suitability of the so-called slump test was investigated at KTH. This test is already well established in cement concrete technology but was not considered meaningful for asphalt materials, so far [25]. Since the slump test is comparatively simple to perform for cement concrete, it was considered as good potential candidate for practical use on asphalt plants and on construction sites, fully being aware that temperature and viscous behavior of asphalt may be the critical challenge. Practical experiments were conducted on stone mastic asphalt SMA16 with pen graded bitumen $70 / 100$ at mixture temperatures $145 \pm 10^{\circ} \mathrm{C}$ and modelled with DEM from a microstructural point of view with clustered particles as shown in Fig 6 a.

Focusing particularly on the influence of binder content on the height of the slumped material cone (slump height), satisfactory agreement between DEM model simulation and experimental measurement was found. This means that the numerical approach is suitable for modelling the microstructural interactions within a mixture, thus capturing its macroscopic flow response in a reasonable way under changed particle contact conditions, as shown in Fig $6 \mathrm{~b}$. Bond strengths were numerically evaluated based on plausibility consideration (Fig 6c), demonstrating that bonding strength must be zero in case of no binder, but reaches a maximum in case of very thin binder film before becoming significantly lower when the binder film gets thicker. These phenomena are well known from the gluing theory. As for friction, in all cases, a coefficient of $\mu=0.5$ was assumed, except for high binder content $(\mu=0.25)$ where plausibility considerations suggest that the influence of asperities becomes negligibly low.

From the combined experimental and numerical DEM analysis was concluded, that the flow in a mixture can be physically interpreted as a combined effect of lubricated friction and bonding force. Moreover it was concluded that the slump test explicitly represents the free flow behavior of asphalt in an asphalt plant, e.g. when emptying the mixer into a truck for transportation or emptying the truck into the receiving hopper of a paver. Hence, it was found to be a promising experimental tool for studying the flow of uncompacted asphalt mixtures in the construction phase of a pavement with acceptable repeatability and should therefore be further developed and optimized.

Based on the results with the quasi-static slump test, another novel test was created and combined with DEM for inquiring vibration-induced segregation as found on bumping trucks on their way from the asphalt plant to the construction site. First results demonstrate that the largest particles show greatest tendency to segregate, tending to rise up on top of the smaller ones, and that the segregation potential appears to increase with continuous vibration in a nonlinearly proportional way to vibration time [26].

\subsection{Material flow during compaction}

As for evaluating compactability and material flow in the early stage of compaction, a new type of test has been developed recently in a PhD study at $\mathrm{KTH}[27,28]$, the so-called compaction flow test (CFT), for roughly simulating the flow of particles in asphalt mixtures under compacting loads in the laboratory. The unbound material is filled flush into a cubical $150 \times 150 \times 100 \mathrm{~mm}^{3}$ aluminum mold and continuously loaded with constant displacement speed $15 \mathrm{~mm} / \mathrm{min}$ from one side of the surface down to a defined depth with a prismatic $50 \mathrm{~mm}$ wide loading strip. This creates an uplift of material on the free surface of the specimen, as shown in Fig. $7 a, b$. Load and uplift are measured as indicator of the potential of material flow.

The CFT was developed by combining mechanical tests on unbound model and real aggregates as well as real $A C 11$ and SMA 11 with X-Ray-CT imaging and DEM modeling. Fig 7c depicts an example of a force-loading strip displacement curve for an asphalt concrete AC11 and a stone mastic asphalt SMA11. Clearly, the coarser SMA 11 mixture requires much more force to create the same vertical displacement under the loading strip, due to its higher resistance against vertical deformation. On the other hand (Fig 7d) SMA 11 produces higher uplift and higher horizontal movements due to its skeleton type stone structure (Fig 1) as indicated by the displacement vectors obtained from embedded steel screws serving as direction pointers for better contrast in the X-RayCT images. 


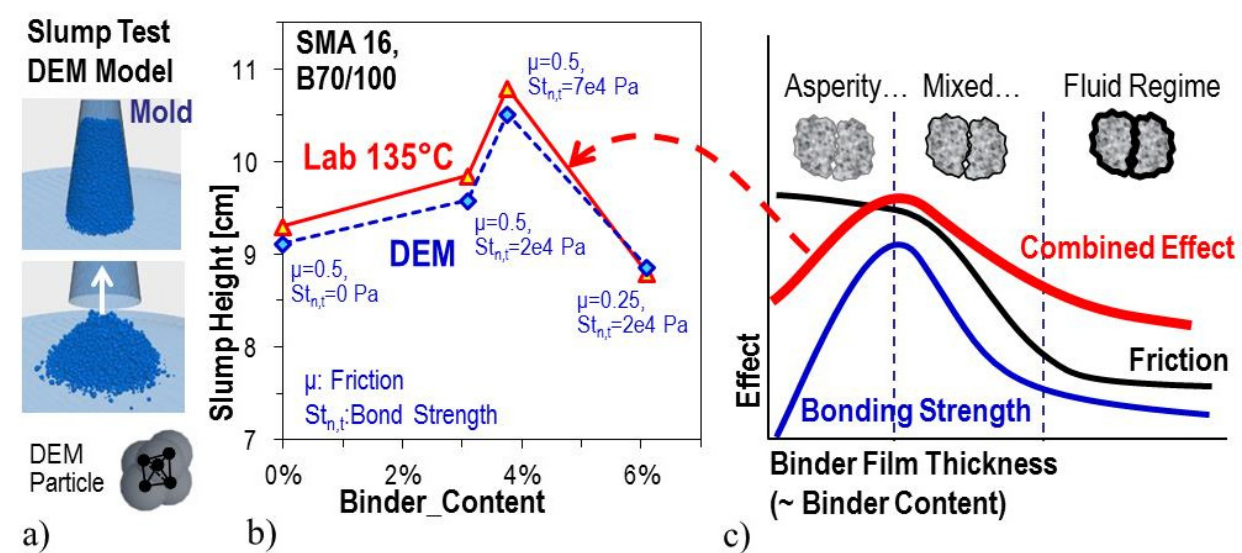

Figure 6. a) Principle of slump test and DEM modelling with clustered particles when removing the mold; b) comparison of model and experiment showing slump height vs. binder content; c) schema of the effect of friction and bonding as a function of binder thickness.

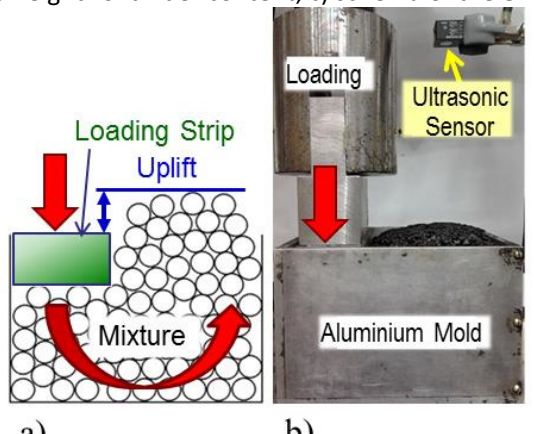

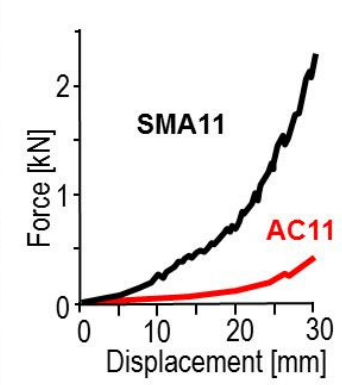

c)



d)

Figure 7. a) Principle of compaction flow test CFT; b) experimental setup showing ultrasonic sensor for measuring material uplift; c) comparison of force-loading strip displacement for two mixtures; d) comparison of movement vectors of screw pointers, determined with CT.

\subsection{Construction joints}

The experimental and modelling tools mentioned above can also be applied for improving design and service life of construction joints. Research in this direction has been performed at KTH in close relationship with the development of the CFT and refinement of DEM [29]. At the same time, research at Empa has investigated the effect of using inductively active material in the neighborhood of joints for both inductive healing at a later stage of service life and inductive improvement of the bond of new joints as an additional construction step [30,31]. Focus in both cases was the search for joints and concepts that would allow transferring traffic loads on a pavement layer with joints in an equal or similar way as in case of a quasi-monolithic layer without joints.

Resent research at KTH demonstrated that CFT as well as DEM are both useful tools for studying and optimizing construction joint issues [29]. It was shown that geometry of the joint interface was a major key for improving the load transfer properties of asphalt pavement joints. Moreover, as concluded in an earlier experimental study [32], compaction from the hot side towards the cold side of the joint appeared better for the quality of joints than common compaction from the cold to the hot side of the joint. Finally, compacting the asphalt on a properly designed rough surface, for keeping the mineral aggregates of the mixture close to the joint, may positively affect the service life of asphalt joints.

As for the effect of applying inductively active asphalt for joints, four point bending tests at $0^{\circ} \mathrm{C}$ on specimens $40 \times 40 \mathrm{x}$ $500 \mathrm{~mm}^{3}$ and APT traffic simulation at $20^{\circ} \mathrm{C}$ on $1600 \times 600 \mathrm{x}$ $40 \mathrm{~mm}^{3}$ slabs with the MMLS in the laboratory were performed [30, 31]. AC11 mixtures with and without $14 \mathrm{wt} \%$ (of mixture) of $0.6-1 \mathrm{~mm}$ iron particles were used. The results suggest that the application of induction technology may improve both load transfer and service life of longitudinal asphalt joints considerably. This is particularly encouraging under the aspect that repeated induction heating allows reactivating the interlock of the joint during service life.

However, performance of the joint clearly depends on the chosen joint design. One positive example is the case of joint design with a naturally inclined joint surface structure, where the $130^{\circ} \mathrm{C}$ hot $A C 11$ mixture was placed close to a $22^{\circ} \mathrm{C}$ cold AC 11 lane [30]. Then, additional induction heating treatment was applied, followed by a final post compaction with a $105 \mathrm{~kg}$ hand roller. In the quasi-static bending test, fracture occurred a few centimeters apart from the joint under three times higher breaking forces at $0^{\circ} \mathrm{C}$ than for the comparable joint design $A$ without induction.

Positive but less favorable results were also observed even in case of vertical joints after similar treatment [31]. The experimental setup and the corresponding MMLS results are 
shown in Fig 8. Obviously, vertical joint design E with combined induction and post-compaction treatment lasted about 8 times longer that the design $A$ without treatment. The discontinuous curves in case of design $E$, are due to the fact that the test had to be interrupted overnight. The reason for larger strain amplitudes for the left strain gauge comes from the fact that the wheel was running just on the right side of the joint. The fact that the left strain gauge shows no abrupt decrease demonstrates the good load transfer in case of design $\mathrm{E}$.



Figure 8. a) Setup for MMLS testing of construction joints; b) strain amplitudes at different locations vs. passings for joint design A (no induction) and $E$ (with induction treatment).

\section{Conclusions}

Selected results and initiatives in modern asphalt pavement research at the Swiss Federal Laboratories for Material Science and Technology (Empa) and the Swedish Royal Institute of Technology (KTH), for improving service life of asphalt materials and roads, are summarized. Examples of new experimental and numerical modelling approaches are presented leading to the following general main conclusions. Broad knowledge and a variety of scientific and technological possibilities for improving service life of asphalt roads are already available for modifying existing materials or for designing performance oriented new pavement materials. In order to reduce the risk of failure under service conditions, such research and development initiatives should cover the whole multi-scale range, from nano- to macro- level, using refined sophisticated experimental and numerical computational tools. However, these initiatives should not only rely on refined experiments and models but also on careful validation with APT in order to avoid bad surprises in the field. As for theoretical modelling, DEM appears promising, in particular in cases where large deformations have to be expected, e.g. in the construction phase. However, determining reliable input data for such computational tools may be quite a difficult task.
Focus must not only lie on material and structure of pavements but also on pavement properties and behavior in the production and construction phase. Issues such as workability and compactability still need considerable research effort and, in particular, improvement in collaboration and understanding between practitioners.

Research and development must not only care for classical functionality issues but also for multifunctionality in order to increase the benefit of roads. In the quest for ways of boosting service life and sustainable use of road materials, it is necessary that our community learns to implement healing concepts in practice and use marginal and waste materials without creating linear landfills. We should also learn to improve low-temperature asphalt construction technology [33].

Future trends suggest that asphalt roads become more and more high tech structures, build of thermoplastic material where bitumen is only a source for tailoring affordable synthetic binders, thus turning asphalt to "plasphalt". This should not occur at cost of recyclability, of course. However, introducing new material components and production ways requires out-of-the-box thinking, based on both a sound scientific and engineering background, which can only be established through competent professional education in an academic and practical environment. Therefore, it has to be understood by the professional community, but also by universities and decision makers, that asphalt pavement technology is indeed turning from a mainly phenomenological experience driven "low tech" to a scientifically demanding and innovation boosting "high-tech" domain.

\section{References}

[1] M. N. Partl. Towards improved Testing of Modern Asphalt Pavements. Mater Struct (2018) 51:166. https://doi.org/10.1617/s11527-018-1286-9

[2] M. N. Partl, C. Raab, M. Arraigada. Innovative Asphalt Research using Accelerated Pavement Testing. J Marine Sci Technol JMST (2015) 23 (3): 269-280.

[3] L. D. Poulikakos, S. dos Santos, M. Bueno, S. Kuentzel, M. Hugener, M. N. Partl. Influence of Short and Long Term Aging on Chemical, Microstructural and Macro-mechanical Properties of Recycled Asphalt Mixtures. Constr Build Mater (2014) 51: 414-423. https://doi.org/10.1016/i.conbuildmat.2013.11.004

[4] M. N. Partl, H. U. Bahia, F. Canestrari, C. De La Roche, H. Di Benedetto, H. Piber, D. Sybilski (eds). Advances in Interlaboratory Testing and Evaluation of Bituminous Materials. RILEM State-of-the-art report, 9 , Springer (2013). https://doi.org/10.1007/978-94-007-5104-0

[5] M. N. Partl, L. Porot, H. Di Benedetto, F. Canestrari, P. Marsac, G. Tebaldi (eds) (2018) Testing and Characterization of Sustainable Bituminous Materials and Systems. RILEM State-of -the-art report, 24, Springer (2018).

[6] W. G. Buttlar, A. Chabot, E. V. Dave, C. Petit, G. Tebaldi (eds) Mechanisms of Cracking and Debonding in Asphalt and Composite Pavements. RILEM state-of-the-art report, 28, Springer (2018). https://doi.org/10.1007/978-3-319-76849-6

[7] M. N. Partl, G. Tebaldi (eds). Environmental Innovations for Asphalt Pavements, Road Mater Pavement Des (2017) 18:2. https://doi.org/10.1080/14680629.2016.1213521

[8] M. Hugener, A., Kawakami. Simulating Repeated Recycling of Hot Mix Asphalt, Road Mater Pavement Des (2017) 18:sup2: 76-90. https://doi.org/10.1080/14680629.2017.1304263

[9] M. C. Cavalli. Exploring Fundamental Aspects of Bio-Modified Reclaimed Asphalt Binder. PhD Thesis ETH Zurich No 25230 (2018) 
[10] M. C. Cavalli, M. N. Partl, L. D. Poulikakos. Measuring the Binder Film Residues on Black Rock in Mixtures with High Amounts of Reclaimed Asphalt, J. of Cleaner Production 149 665-672 (2017). https://doi.org/10.1016/j.jclepro.2017.02.055

[11] S. dos Santos, M. N. Partl, L. D. Poulikakos. Newly Observed Effects of Water on the Microstructures of Bitumen Surface. Constr Build Mater (2014) 71: 618-627. https://doi.org/10.1016/j.conbuildmat.2014.08.076

[12] F. Piemontese, M. Arraigada, H. Hugener. Forschungspaket Recycling von Ausbauasphalt in Heissmischgut: VP6 In-situ Validierung. Eidg. Dept. für Umwelt, Verkehr, Energie \& Kommunikation, Bundesamt für Strassen. VSS 2008/401 Rep. Nr. 1636, July (2018). In German

[13] M. Arraigada, F. Piemontese, M. Hugener, M.N.Partl. Field Validation of High Content Recycled Asphalt Concrete Mixtures with Accelerated Pavement Testing (pp. 1-7). ISAP Conference. Fortaleza, Brazil (2018). https://www.dora.lib4ri.ch/empa/islandora/object/empa:17318

[14] A. Garcia, M. Bueno, J. Norambuena-Contreras, M. N. Partl. Influence of Steel Wool Fibers on the Mechanical, Thermal and Healing Properties of Dense Asphalt Concrete. J Test Eval (2014) 42(5): 1-12. https://doi.org/10.1520/JTE20130197

[15] E. Jeoffroy, D. Koulialias, S.Yoon, M. N. Partl, A. R. Studart. Iron Oxide Nano-particles for Magnetically-Triggered Healing of Bituminous Materials. Constr Build Mater (2016) 112: 497-505. https://doi.org/10.1016/i.conbuildmat.2016.02.159

[16] M. Bueno, M. Arraigada, M. N. Partl. Damage Detection and Artificial Healing of Asphalt Concrete after Trafficking with a Load Simulator. Mech Time-Depend Mater (2016) 20(3): 265-279. https://doi.org/10.1007/s11043-016-9306-z

[17] Z. Refaa, M.R. Kakar, A. Stamatiou, J. Worlitschek, M.N. Partl, M. Bueno. Numerical Study on the Effect of Phase Change Materials on Heat Transfer in Asphalt Concrete. Int J Therm Sci (2018) 133: 140150. https://doi.org/10.1016/j.jithermalsci.2018.07.014

[18] M. R. Kakar, Z Refaaa, J. Worlitschek, A. Stamatiou, A., M. N. Partl, M. Bueno. Investigating Bitumen's Direct Interaction with Tetradecane as Potential Phase Change Material for Low Temperature Applications. Road Mater Pavement Des (2019) 1-8. https://doi.org/10.1080/14680629.2019.1601127

[19] M. R. Kakar, Z Refaaa, J. Worlitschek, A. Stamatiou, A., M. N. Partl, M. Bueno. Thermal and Rheological Characterization of Bitumen Modified with Microencapsulated Phase Change Materials. Constr Build Mater (2019) 215: 171-179. https://doi.org/10.1016/j.conbuildmat.2019.04.171

[20] S. Lal, M. Prat, M. Plamondon, L.D. Poulikakos, M.N. Partl, D. Derome, J. Carmeliet. A Cluster-based Pore Network Model of Drying with Corner Liquid Films, with Application to a Macroporous Material. Int J Heat Mass Tran (2019) 140: 620-633. https://doi.org/10.1016/j.ijheatmasstransfer.2019.06.016

[21] S. Son. Lattice Boltzmann Modeling of Two-phase Flow in Macroporous Media with Application to Porous Asphalt. PhD Thesis ETH Zurich, No. 23627 (2016)

[22] N.A. Conzelmann, L. Gorjan, F. Sarraf, L. D. Poulikakos, M. N. Partl, C. R. Müller, F. J. Clemens. Manufacturing Complex Al2O3 Ceramic Structures Using Consumer-grade Fused Deposition Modelling Printers, Rapid Prototyping Journal (2020). https://doi.org/10.1108/RPJ-05-2019-0133

[23] P. Aejmelaeus-Lindstrom, J. Willmann, S. Tibbits, F. Gramazio, M. Kohler. Jammed Architectural Atructures: Towards Large-scale Reversible Construction. Granul Matter (2016) 18(2): 1-12. https://doi.org/10.1007/s10035-016-0628-y

[24] Project Info on Robotic Reinforcement of Pavements ASTRA 2017/005:https://www.aramis.admin.ch/Texte/?ProjectID=40744 (accessed 2020).

[25] F. Chen, D. Jelagin, M.N. Partl. Experimental and Numerical Analysis of Asphalt Flow in a Slump Test. Road Mater Pavement Des (2019) 20:sup1: 446-461. https://doi.org/10.1080/14680629.2019.1587495

[26] F. Chen, D. Jelagin, M.N. Partl. Vibration Induced Aggregates Segregation in Asphalt Mixtures. Mater Struct (2020) 53: 27. https://doi.org/10.1617/s11527-020-01459-y

[27] E. Ghafoori Roozbahany. Flow Behavior of Asphalt Mixtures under Compaction. PhD thesis KTH Stockholm, TRITA-BYMA, 2017:07 (2017).

[28] E. Ghafoori Roozbahany, M.N. Partl. A New Test to Study the Flow of Mixtures at Early Stages of Compaction. Mater Struct (2016) 49(9): 3547-3558. https://doi.org/10.1617/s11527-015-0738-8
[29] E. Ghafoori Roozbahany, M. N. Partl. Investigation of Asphalt Joint Compaction using Discrete Element Simulation. Road Mater Pavement Des (2019) 20(7): 1722-1734. https://doi.org/10.1080/14680629.2019.1594055

[30] [30] M. Bueno, M. Arraigada, M. N. Partl. Induction Heating Technology Applied for Improving Compaction of Asphalt Joints. Int J Pavement Eng (2018). https://doi.org/10.1080/10298436.2018.1554218

[31] M. Arraigada, M. Bueno, M. N. Partl. Down-Scaled Accelerated Trafficking of Novel Asphalt Joints Based on the Induction Heating Technology, accepted for 6th international conference on Accelerated Pavement Testing in Nantes (APT2020), Sept. 21-23 (2020).

[32] E. Ghafoori Roozbahany, M. N. Partl, P-J. Witkiewicz. Fracture Testing for the Evaluation of Asphalt Pavement Joints. Road Mater Pavement Des (2013) 14(4): 764-791. https://doi.org/10.1080/14680629.2013.812979

[33] C. Raab, M. N. Partl. Laboratory Evaluation and Construction of Fully Recycled Low-Temperature Asphalt for Low-Volume Roads, Adv Mater Sci Eng (2020) 2020: 4904056. https://doi.org/10.1155/2020/4904056 